\title{
Orally delivered resveratrol-loaded lipid-core nanocapsules ameliorate LPS-induced acute lung injury via the ERK and PI3K/Akt pathways
}

This article was published in the following Dove Press journal: International Journal of Nanomedicine

\author{
Maria Talita Pacheco \\ de Oliveira' \\ Diego de Sá Coutinho' \\ Éverton Tenório de Souza' \\ Sílvia Stanisçuaski Guterres ${ }^{2}$ \\ Adriana Raffin Pohlmann ${ }^{3}$ \\ Patricia Machado Rodrigues \\ Silva' \\ Marco Aurélio Martins' \\ Andressa Bernardi \\ 'Laboratory of Inflammation, Oswaldo Cruz \\ Institute, Oswaldo Cruz Foundation, Rio de \\ Janeiro, Brazil; ${ }^{2}$ Pharmaceutical Sciences \\ Post-Graduation Program, College of \\ Pharmacy, Federal University of Rio Grande \\ do Sul, Porto Alegre, Brazil; ${ }^{3}$ Department of \\ Organic Chemistry, Institute of Chemistry, \\ Federal University of Rio Grande do Sul, \\ Porto Alegre, Brazil
}

Correspondence: Andressa Bernardi Oswaldo Cruz Foundation/FIOCRUZ, Av. Brasil 4365, Manguinhos, Rio de Janeiro 21040-360, Brazil

Email andressa.bernardi@ioc.fiocruz.br
Background: Resveratrol (RSV) has attracted interest as an alternative drug for the treatment of acute lung injury (ALI) and other pulmonary diseases, but its poor oral bioavailability is a limitation. In this study, we employed drug delivery nanotechnology to improve the stability, lung localization and efficacy of orally administered resveratrol to control lung damage leading to ALI.

Methods and materials: RSV-loaded lipid-core nanocapsules (RSV-LNCs), prepared by interfacial deposition of biodegradable polymers, were given orally to $\mathrm{A} / \mathrm{J}$ mice prior to lipopolysaccharide (LPS) intranasal instillation. Inflammatory changes, oxidative stress and lung tissue elastance were assessed $24 \mathrm{~h}$ after LPS challenge.

Results: RSV-LNCs $(5 \mathrm{mg} / \mathrm{kg})$, given $1,4,6$ or $12 \mathrm{~h}$ but not $24 \mathrm{~h}$ before provocation, inhibited LPS-induced leukocyte accumulation in the bronchoalveolar fluid (BALF), whereas unloaded nanocapsules (ULNCs) or free RSV $(5 \mathrm{mg} / \mathrm{kg}$ ) were ineffective. RSV-LNCs $(2.5-10 \mathrm{mg} / \mathrm{kg}$ ) but not ULNCs or RSV improved lung function and prevented total leukocyte and neutrophil accumulation equally in both BALF and lung tissue when given $4 \mathrm{~h}$ before LPS challenge. Similar findings were seen concerning the generation of a range of pro-inflammatory cytokines such as IL-6, KC, MIP-1 $\alpha$, MIP-2, MCP-1 and RANTES in lung tissue. In addition, only RSV-LNCs inhibited MDA levels and SOD activity in parallel with blockade of the ERK and PI3K/Akt pathways following LPS provocation.

Conclusion: Nanoformulation of RSV in biodegradable oil-core polymers is an effective strategy to improve the anti-ALI activity of RSV, suggesting that the modified-release formulation of this plant polyphenol may be of great value in clinical conditions associated with ALI and respiratory failure.

Keywords: biodistribution, drug delivery, anti-inflammatory effect, nanostructured lipid carriers

\section{Introduction}

Inflammation has been shown to underlie diseases triggered by a variety of noxious stimuli, including infection and injury. ${ }^{1,2}$ Lipopolysaccharide (LPS) stimulation is widely used to promote an intense inflammatory response via activation of Toll-like receptor 4 (TLR4). ${ }^{3}$ Airway instillation with bacterial LPS is a well-established model often used to mimic acute respiratory distress syndrome (ARDS) in experimental trials. ${ }^{4,5}$ ARDS is a serious and potentially fatal pulmonary inflammatory disease characterized by respiratory failure, atelectasis, and damage to pulmonary mechanics and gas exchange as a consequence of endothelial cell damage caused by 
inflammation, apoptosis, and necrosis. In addition to its high mortality rate (30-45\%), ARDS reduces the quality of life for survivors and can affect patients in all age groups. ${ }^{6-9}$

First described in 1939 by Takaoka, ${ }^{10}$ resveratrol (3,5,4'-trihydroxystilbene, RSV) is a plant polyphenol produced in a range of species such as grapes, berries and peanuts as a defense mechanism against environmental stressors such as pathogens, UV radiation and others. ${ }^{11,12}$ RSV became known after the use of "French paradox", a term based on epidemiological studies that related the moderate consumption of red wine with a low incidence of coronary diseases, despite the saturated fat-rich diet, smoking and low physical activity, in the French population. ${ }^{13}$ Later, studies confirmed the cardioprotective activity and many pharmacological effects of RSV. ${ }^{14,15}$

This polyphenol exists as two optical isomers, cis and trans, with the latter known to be more stable, abundant and biologically active, ${ }^{16-18}$ although trans-RSV to cisRSV isomerization may occur upon exposure to light or acidic $\mathrm{pH} .{ }^{19}$ Low solubility in water $(3 \mathrm{mg} / 100 \mathrm{~mL})$ and high permeability facilitate the passage of RSV through biological membranes and allow its interaction with multiple intracellular targets, ${ }^{20-22}$ including molecules from the MAPK, AP $-1^{23}$ and NF- $\kappa B^{24}$ cascades. RSV can also act as a free radical receptor by increasing the activity of antioxidant enzymes such as glutathione peroxidase. ${ }^{25}$

RSV has been shown to produce a broad spectrum of pharmacological effects, including antioxidant, ${ }^{26}$ antiaging, ${ }^{27}$ anti-carcinogenic, ${ }^{28}$ anti-inflammatory ${ }^{29}$ and cardioprotective effects, ${ }^{30}$ that could facilitate its therapeutic application in clinical conditions. Nevertheless, the oral bioavailability of this polyphenolic compound is very low due to its incomplete intestinal absorption, intense catabolism and elimination through $\mathrm{ABC}$ transporters, which limits its potential application as a therapeutic agent. $^{31,32}$ A number of pharmaceutical approaches involving modified-release formulations have been undertaken to surmount these limitations, including the incorporation of RSV into gelatin nanoparticles, ${ }^{33}$ liposomes, ${ }^{34}$ and solid lipid nanoparticles ${ }^{35}$ and nanocomplexation with isolated soy protein, ${ }^{20}$ polymeric micelles $^{36}$ and polymeric nanoparticles. ${ }^{37}$

Prior investigation showed that RSV (25 mg/kg, oral) alleviated the pathological features of acute lung injury (ALI) in no more than $50 \%$ of mice when given daily for 3 days prior to LPS challenge. ${ }^{38}$ Therefore, the present study was undertaken in order to evaluate whether or not nanostructuration in biodegradable oil-core polymers might be a means to improve the potency and efficacy of RSV treatment in experimental ALI.

\section{Materials and methods Preparation of RSV-LNCs}

We used interfacial deposition of the polymer to prepare the nanoformulation of RSV (RSV-LNCs) according to previously published methods. ${ }^{37}$ In summary, at $40{ }^{\circ} \mathrm{C}$, acetone $(27 \mathrm{~mL})$ was used to dissolve trans-RSV $(0.010 \mathrm{~g})$, poly ( $\varepsilon$-caprolactone) $(0.100 \mathrm{~g})(\mathrm{MW}=65,000)$, capric/caprylic triglyceride $(0.33 \mathrm{~mL})$ and sorbitan monostearate $(0.038 \mathrm{~g})$, while in a separate flask, polysorbate $80(0.038 \mathrm{~g})$ was added to water MilliQ ${ }^{\circledR}(53 \mathrm{~mL})$. The organic solution was injected into the aqueous phase under magnetic stirring at room temperature. After mixing these solutions for $10 \mathrm{~min}$, acetone was evaporated, and the suspensions were concentrated to $10 \mathrm{~mL}$ under reduced pressure. Drug-unloaded nanocapsules (ULNCs) were prepared as described above but without the addition of trans-RSV.

\section{Physicochemical characterization of RSV-LNCs}

For each formulation, analyses were performed using 3 different batches in triplicate. A B-474 potentiometer (Micronal, Brazil) was used to determine the $\mathrm{pH}$. Then, nanoformulations were diluted with $\mathrm{MilliQ}^{\circledR}$ water or aqueous $\mathrm{NaCl}$ solution to determine the mean diameters (z-average), polydispersity and zeta potentials using a Zetasizer $^{\circledR}$ nano-ZS ZEN 3600 model (Nanoseries, Malvern, UK). The size and polydispersity indices were calculated using the software (Dispersion Technology Software-DTS Nano-Version 5.02, Malvern) provided by the manufacturer (Malvern Instruments Ltd).

\section{Analytical procedure}

RSV was analyzed by high-performance liquid chromatography (HPLC) at $306 \mathrm{~nm}$. The content (total concentration) of $\mathrm{RSV}$ in the formulations $(100 \mu \mathrm{L})$ was determined after dissolving the lipid-core nanocapsules containing RSV into acetonitrile $(10 \mathrm{~mL})$ and filtering (Millipore $\left.{ }^{\circledR} 0.45 \mu \mathrm{m}\right)$ for analysis. The system consisted of a UV-Vis detector, pump and auto-injector S200 Perkin-Elmer (PerkinElmer Instruments, Norwalk, CT, USA), and a Shim-pack CLC-C8 (M) column (150 mm, $4.6 \mathrm{~mm}, 5 \mu \mathrm{m}$, Shimadzu Corporation, Japan) with a guard column. The mobile phase was prepared by using Milli- $\mathrm{Q}^{\circledR}$ water and HPLC grade acetonitrile and consisted of acetonitrile/water (40:60 v/v) with a $\mathrm{pH}$ of 3.0 
\pm 0.5 corrected with $10 \%(\mathrm{v} / \mathrm{v})$ orthophosphoric acid. The isocratic flow rate of the mobile phase was $1.2 \mathrm{~mL} / \mathrm{min}$ and the retention time of RSV was $3.45 \mathrm{~min}$. The encapsulation efficiency was determined by ultrafiltration-centrifugation technique (Microcon, 10,000 MW, Millipore), at 15,300 $\times \mathrm{g}$ for $10 \mathrm{~min}$. The associated RSV within the nanocapsules was calculated from the difference between the total and the free drug concentrations determined in the nanocapsule suspension and in the ultrafiltrate, respectively.

\section{Animals}

Experimental protocols and procedures were performed in accordance with the guidelines of the Guide for the Care and Use of Laboratory Animals and approved by the Animal Ethics Committee of the Oswaldo Cruz Foundation (Protocol L-006/2016; Comissão de Ética no Uso de Animais-FIOCRUZ). In this study, male $\mathrm{A} / \mathrm{J}$ mice were kept in the animal housing facilities provided by the Oswaldo Cruz Foundation (FIOCRUZ, Rio de Janeiro, Brazil). Animals (5 per cage) were maintained under controlled conditions at room temperature $\left(22-25^{\circ} \mathrm{C}\right)$, with a $12-$ $\mathrm{h}$ light-dark cycle ( 6 am- $6 \mathrm{pm})$ and food and water ad libitum.

\section{Treatment protocol}

Trans-RSV (Sigma-Aldrich) was solubilized in absolute ethanol $(10 \mathrm{mg} / \mathrm{mL})$ and redispersed in saline to a final concentration of $1 \mathrm{mg} / \mathrm{mL}$ (in $10 \%$ ethanol) immediately before administration. Treatments with RSV or RSV-LNCs at doses of $2.5,5$, or $10 \mathrm{mg} / \mathrm{kg}$ were given orally at $1,4,6$ or $12 \mathrm{~h}$ before the LPS challenge. Dexamethasone $(5 \mathrm{mg} /$ $\mathrm{kg}$ ) was given orally $4 \mathrm{~h}$ before the LPS challenge. For the vehicle control, the animals were treated with the same amount of ULNCs as in the highest dose of RSV used. The analyses were performed $24 \mathrm{~h}$ after the LPS challenge.

\section{Murine model of LPS-induced ARDS}

Experimental ARDS was induced as previously described. ${ }^{39,40}$ After anesthesia with isoflurane aerosol and constant $\mathrm{O}_{2}$ flow (3.5 kgf $/ \mathrm{cm}^{2}$; BRASMED, Guarulhos, Brazil), mice were subjected to LPS intranasal instillation $(25 \mu \mathrm{g})$ in saline $(25 \mu \mathrm{L})$. Control animals received only saline.

\section{Invasive assessment of respiratory mechanics}

To measure airway hyperreactivity (AHR) changes in airway function were assessed after challenge with aerosolized methacholine using a FinePoint R/C Buxco Platform
(Buxco Electronics, Sharon, CT, USA), as previously reported. ${ }^{41}$ First, mice were anaesthetized with sodium pentobarbital $(60 \mathrm{mg} / \mathrm{kg}$ intraperitoneal; Cristália, Itapira, Brazil), and then the neuromuscular activity was blocked with bromide pancuronium $(1 \mathrm{mg} / \mathrm{kg})$. After tracheostomy, animals were maintained under mechanical ventilation (MiniVent, Buxco Electronics, Wilmington, NC, USA) with only atmospheric air (inspired $\mathrm{O}_{2}$ fraction, $20 \%$ ), and lung function was assessed. Throughout the assay ( $\sim 30$ mins), animals were maintained at $36-36.5^{\circ} \mathrm{C}$ and subjected to baseline mechanical ventilation conditions (tidal volume $=0.25 \mathrm{~mL}$, positive end-expiratory pressure $=0.160 \mathrm{~cm} / \mathrm{H}_{2} \mathrm{O}$, and respiratory frequency $=100$ breaths/ min). Assessment of airflow and transpulmonary pressure was conducted by a DSI-Buxco Electronics Buxco Pulmonary Mechanics Processing System used to calculate lung elastance $\left(\mathrm{mL} \mathrm{cm} / \mathrm{H}_{2} \mathrm{O}\right)$ in each breath cycle. Analog signals were digitized using a DSI-Buxco analog/digital converter (DSI-Buxco Electronics). Mice were stabilized for $5 \mathrm{~min}$, and concentrations of methacholine (3, 9, and $27 \mathrm{mg} / \mathrm{mL}$ ) were aerosolized for $5 \mathrm{~min}$ each to assess AHR. Baseline pulmonary parameters were assessed following aerosol administration of PBS. Data comprised the mean absolute values of the responses collected during the $5 \mathrm{~min}$ after methacholine aerosolization.

\section{Cell recovery from the airway lumen}

The number of leukocytes recovered from bronchoalveolar lavage fluid (BALF) was determined as previously reported. ${ }^{42}$ BALF was centrifuged, and cell pellets were resuspended in PBS containing $10 \mathrm{mM}$ EDTA to determine the total leukocyte count using a Neubauer chamber. Then, cytospin slides were prepared and subjected to MayGrunwald-Giemsa staining. A total of 100 cells were counted using light microscopy and differentiated according to standard morphological criteria.

\section{Myeloperoxidase activity assay}

Perfused lung samples were used to assess myeloperoxidase (MPO) activity, as previously reported. ${ }^{40}$ Briefly, homogenization of lung tissue was performed in Hank's solution. The resulting pellet from centrifugation was suspended in $\mathrm{NaCl}$ and centrifuged. Then, the pellet was suspended in hexadecyltrimethylammonium bromide (HTAB) and recentrifuged. The supernatant was collected, centrifuged, plated with $\mathrm{HTAB}$ and orthodianisidine, and maintained at $37{ }^{\circ} \mathrm{C}$ for $15 \mathrm{~min}$. Finally, $\mathrm{H}_{2} \mathrm{O}_{2}$ was added for $10 \mathrm{~min}$, followed by addition of sodium azide. The absorbance $(460 \mathrm{~nm})$ was 
measured using a SpectraMax M5 plate reader (Molecular Devices LLC, Sunnyvale, CA, USA).

\section{Histological analysis of the lung}

Routine histological techniques were employed as described in our previous study. ${ }^{40} \mathrm{H} \& \mathrm{E}$-stained slides were analyzed regarding inflammatory cell infiltration in the airspace or vessels, congestion of alveoli and thickness of the alveolar wall. A semiquantitative score ranging from 0 to 4 was calculated via a numerical rating system with $0=$ no damage, $1=$ minor damage, $2=$ moderate damage, $3=$ severe damage, and $4=$ very severe damage. ${ }^{40,43}$

\section{Chemokine quantification}

Supernatants from lung tissue were obtained as previously described $^{40}$ and used to measure chemokine levels via an ELISA, according to the manufacturer's instructions (DuoSet $^{\circledR}$; R\&D Systems, Minneapolis, MN, USA). Cytokine levels were normalized to total protein levels.

\section{Oxidative stress analysis}

Lung tissue fragments were homogenized in $500 \mu \mathrm{L}$ of potassium phosphate + EDTA buffer (KPE) $(\mathrm{pH} 7.5)$ and then centrifuged at $600 \mathrm{~g}$ for $10 \mathrm{~min}\left(4^{\circ} \mathrm{C}\right)$. The resulting supernatant was used for analysis of the malondialdehyde (MDA) level and superoxide dismutase (SOD) activity.

\section{Measurement of MDA levels}

MDA levels, as a parameter of lipid peroxidation, were determined using the thiobarbituric acid reactive substances (TBARS) method. ${ }^{44}$ Pulmonary tissue samples $(100 \mu \mathrm{L})$ were mixed in $100 \mu \mathrm{L}$ of $10 \%$ trichloroacetic acid and centrifuged for $15 \mathrm{~min}$ at $3600 \mathrm{~g}$ at $4{ }^{\circ} \mathrm{C}$. Then, the supernatant $(150 \mu \mathrm{L})$ was collected, and $150 \mu \mathrm{L}$ of thiobarbituric acid was added. Samples were heated at $95^{\circ} \mathrm{C}$ for $10 \mathrm{~min}$. MDA levels were determined by absorbance $(532 \mathrm{~nm}$ ) (SpectraMax M5, Molecular Devices) and expressed as $\mathrm{nm} / \mathrm{mg}$ protein.

\section{Quantification of SOD activity}

SOD activity was evaluated by measuring inhibition of the adrenaline auto-peroxidation product, as previously described. ${ }^{45}$ Briefly, KPE processed samples were added to a 96-well plate at three different volumes $(1 \mu \mathrm{L}, 2 \mu \mathrm{L}$ and $3 \mu \mathrm{L}$ ); then, $197 \mu \mathrm{L}$ of glycine buffer ( $\mathrm{pH} 10.2), 2 \mu \mathrm{L}$ of catalase and $4 \mu \mathrm{L}$ of epinephrine (Sigma Aldrich) were added, and a reading was immediately taken using a spectrophotometer (SpectraMax M5, Molecular Devices) at $480 \mathrm{~nm}$. A control for free oxidation of epinephrine without the sample was used.

\section{Western blot analysis}

Lung tissue was prepared for Western blot analysis according to the method used in our previous study. ${ }^{40}$ In summary, samples homogenized with RIPA buffer were quantified for total proteins and then denatured. Equal amounts of proteins were separated using SDS-polyacrylamide gel electrophoresis. After transfer to nitrocellulose membranes, proteins were incubated with primary antibodies against ERK1/2 (1:1,000; Cell Signaling, Danvers, MA, USA) and AKT (1:1,000; Cell Signaling, Danvers, MA, USA). After incubation with secondary antibodies, immunocomplexes were visualized using $\mathrm{X}$-ray films (Kodak ${ }^{\mathrm{TM}}$; PerkinElmer). Band density measurements were performed using ImageJ software. Data are presented as the ratio of phosphorylated protein to total protein. Uniform gel loading was confirmed with $\beta$-actin $(1: 1,000$; Abcam, Cambridge, UK) as the standard.

\section{Statistical analysis}

Statistical analyses were conducted with ANOVA followed by a Newman-Keuls post hoc test or Tukey's multiple comparison test using GraphPad Prism software Version 5.01 (GraphPad Software, La Jolla, CA, USA). Two-way ANOVA was also performed followed by a Bonferroni posttest for lung function analyses. $P$-values $<0.05$ were considered statistically significant for both tests.

\section{Results}

\section{Preparation and characterization of RSV nanocapsules}

Resveratrol-loaded and unloaded lipid-core nanocapsules (RSV-LNCs and ULNCs, respectively) employed in the current study had been previously developed and successfully used to treat experimental Alzheimer's disease. ${ }^{37}$ The schematic diagram depicting the structure of the nanocapsules is shown in Figure 1. Both formulations presented as a macroscopically homogeneous white-blue opalescent liquid. RSV-LNCs characterization revealed measurements of $241 \pm 7 \mathrm{~nm}, 0.16 \pm 0.03,-14.1 \pm 2.3 \mathrm{mV}$, and $5.2 \pm 0.3$ for particle size, polydispersity, zeta potential, and $\mathrm{pH}$ values, respectively. For ULNCs characterization revealed measurements of $250 \pm 10 \mathrm{~nm}, 0.15 \pm 0.04,-15.8 \pm 3.0 \mathrm{mV}$, and $5.4 \pm 0.4$ for particle size, polydispersity, zeta potential, and $\mathrm{pH}$ values, respectively. The RSV content in the 


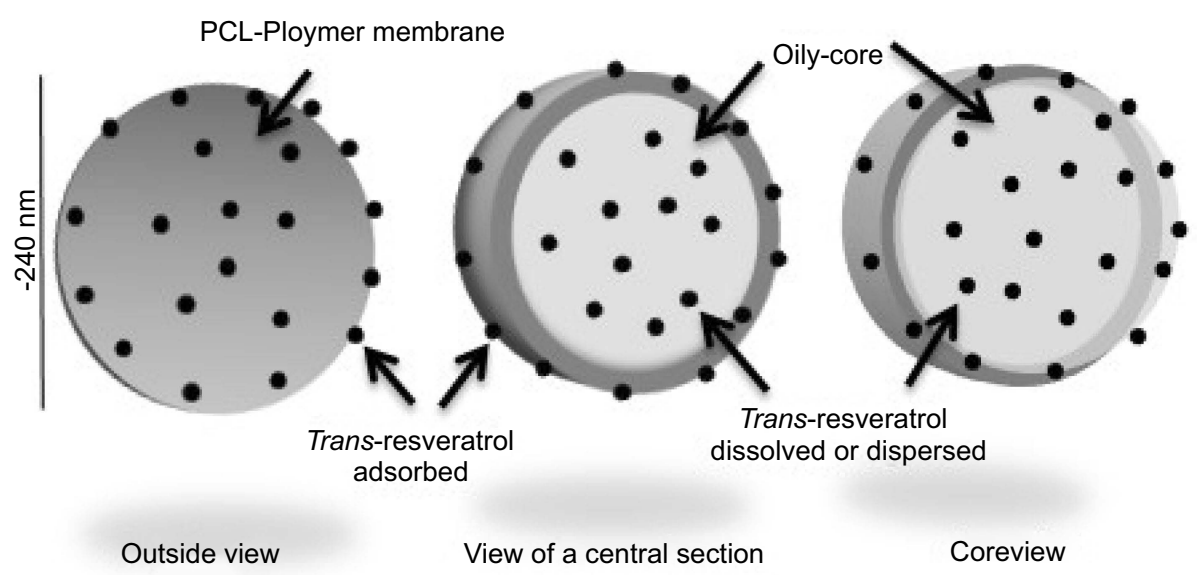

Figure I Graphical representation polymeric oil-core nanocapsules loaded with trans-resveratrol.

nanoformulation was $0.964 \pm 0.037 \mathrm{mg} / \mathrm{mL}$ with an encapsulation efficiency of $99.89 \pm 1.3 \%$.

\section{Time course study}

To investigate the best time for treatment in our mouse model, animals received RSV or RSV-LNCs orally at $1 \mathrm{~h}$, $4 \mathrm{~h}, 6 \mathrm{~h}, 12 \mathrm{~h}$ or $24 \mathrm{~h}$ prior to LPS challenge with the analyses carried out $24 \mathrm{~h}$ later. As shown in Figure 2, RSV $(5 \mathrm{mg} / \mathrm{kg}$ ) failed to alter LPS-induced leukocyte accumulation into the BAL fluid at all time points studied. Notably, RSV-LNCs $(5 \mathrm{mg} / \mathrm{kg}$ ) were clearly active when given either $1 \mathrm{~h}, 4 \mathrm{~h}, 6 \mathrm{~h}$ or $12 \mathrm{~h}$ before provocation but

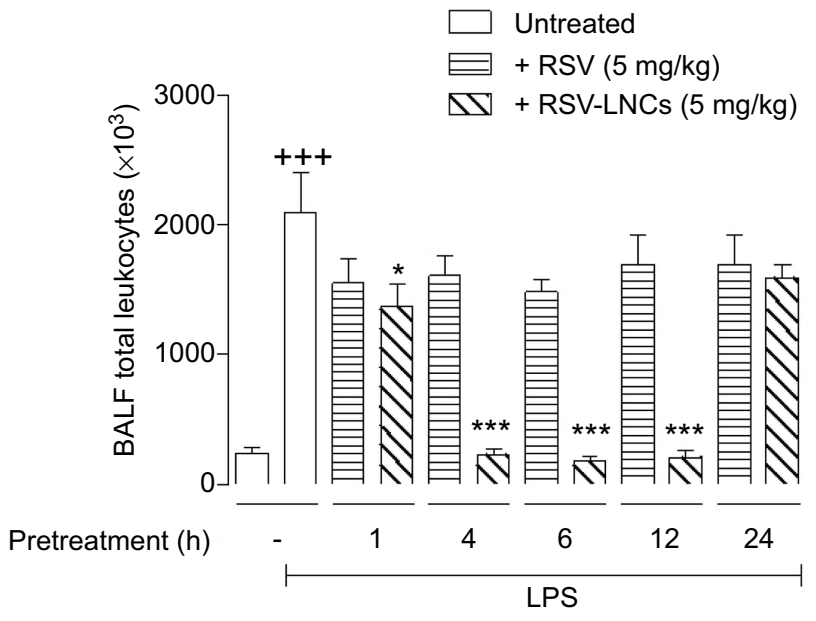

Figure 2 Effect of treatment with RSV or RSV-LNCs on bronchoalveolar accumulation of leukocytes at different time points. A/J mice were orally pretreated with RSV or RSV-LNCs $(5 \mathrm{mg} / \mathrm{kg})$ I h, $4 \mathrm{~h}, 6 \mathrm{~h}, 12 \mathrm{~h}$ or $24 \mathrm{~h}$ before challenge with LPS. BALF leukocytes were assessed $24 \mathrm{~h}$ after LPS provocation.

Notes: Data are expressed as the mean \pm SEM $(n=5-7) .{ }^{+++} P<0.001$ compared with the saline group; $* P<0.05$ and $* * * P<0.001$ compared to the LPS group. Abbreviations: RSV, resveratrol; RSV-LNCs, resveratrol-loaded lipid-core nanocapsules; LPS, lipopolysaccharide. inactive when given $24 \mathrm{~h}$ before, leading us to define the $4 \mathrm{~h}$ pretreatment as fixed for subsequent assays.

\section{RSV-LNCs abolished LPS-induced neutrophilic infiltration into the lung}

As shown in Figure 3A, RSV-LNCs but not RSV abolished LPS-induced total leukocyte accumulation in BAL fluid when orally administered in doses ranging from 2.5 to $10 \mathrm{mg} / \mathrm{kg}$. This inflammatory infiltrate was markedly dominated by neutrophils as attested by differential analyses of cytocentrifuged BAL effluent (Figure 3B) and MPO activity in lung tissue samples (Figure $3 \mathrm{C}$ ), both of which were abolished only by RSV-LNCs (Figure 3B and C). In contrast, unloaded nanocapsules (ULNCs), at an equivalent dose of $10 \mathrm{mg} / \mathrm{kg}$, entirely failed to modify LPS-induced changes in all evaluated parameters (Figure 3A-C). On the other hand, dexamethasone $(5 \mathrm{mg} / \mathrm{kg}$, oral), used as a reference compound, clearly abolished LPS-induced changes in total leukocyte numbers in all evaluated parameters (Figure 3A-C).

In addition to leukocyte infiltration, other pathological features associated with LPS-induced lung damage, including alveolar wall thickening and hemorrhage, were assessed in histological sections stained with H\&E using a semiquantitative score system as reported. ${ }^{40}$ According to these criteria, LPS caused extensive lung pathological changes compared to changes observed in saline-challenged mice (Figure 4B and $\mathrm{A}$, respectively), which were abolished in mice pretreated orally with RSV-LNCs $(2.5,5$ or $10 \mathrm{mg} / \mathrm{kg})$ (Figure 4D, F and H, respectively) but not free RSV (2.5, 5 or $10 \mathrm{mg} / \mathrm{kg}$ ) (Figure 4C, E and G, respectively). Notably, ULNCs did not alter LPS-induced histopathological changes assessed via the semiquantitative score system (Figure 4I). Pretreatment with dexamethasone $(5 \mathrm{mg} / \mathrm{kg}$, oral $)$ also clearly 

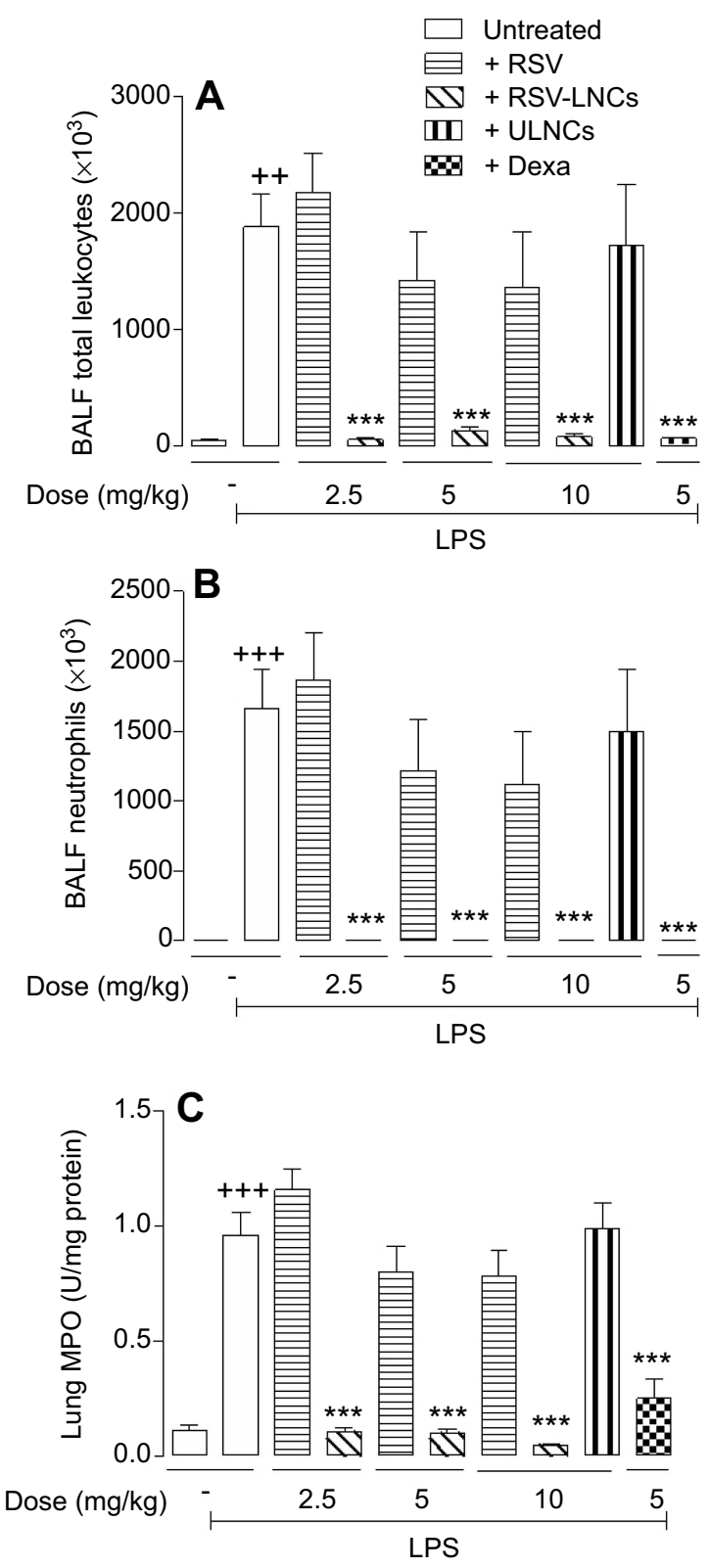

Figure 3 Effect of treatment with RSV or RSV-LNCs on total (A) and differential (B) BALF leukocytes and lung MPO activity (C). A/J mice orally pretreated with RSV, RSV-LNCs $(2.5-10 \mathrm{mg} / \mathrm{kg}$ ), ULNCs or Dexamethasone (Dexa, $5 \mathrm{mg} / \mathrm{kg}$ ) $4 \mathrm{~h}$ before challenge with LPS. Analyses were performed $24 \mathrm{~h}$ after LPS stimulation. Notes: Data are expressed as the mean \pm SEM $(n=5-7) .{ }^{++} P<0.01$ and ${ }^{+++} P<0.001$ compared with the saline group; $* * * P<0.001$ compared to the LPS group. Abbreviations: RSV, resveratrol; RSV-LNCs, resveratrol-loaded lipid-core nanocapsules; Dexa, dexamethasone; MPO, myeloperoxidase; LPS, lipopolysaccharide.

abolished the evaluated pathological changes (Figure 4J). Semiquantitative data are shown in Figure 4K.

\section{RSV-LNCs inhibit LPS-induced}

\section{inflammatory mediators}

As shown in Figure 5, LPS elevated lung tissue levels of IL-6 (Figure 5A), KC (Figure 5B), MIP-1 $\alpha$ (Figure 5C),
MIP-2 (Figure 5D), MCP-1 (Figure 5E) and RANTES (Figure 5F), all of which were inhibited by RSV-LNCs but by neither RSV at doses of $2.5,5$ and $10 \mathrm{mg} / \mathrm{kg}$ nor ULNCs at the equivalent dose of $10 \mathrm{mg} / \mathrm{kg}$. Pretreatment with the reference drug dexamethasone reduced all the evaluated cytokines (Figure 5A-F).

\section{RSV-LNCs inhibit LPS-induced airway hyperresponsiveness}

To measure changes in lung elastance and airway hyperresponsiveness, we assessed lung function after local provocation with the bronchoconstrictor methacholine. As shown in Figure 6, compared with basal controls, LPSstimulated mice showed increased airway hyperreactivity after provocation with methacholine ( 9 and $27 \mathrm{mg} / \mathrm{mL}$ ). This response was abolished when animals were pretreated with RSV-LNCs but not RSV ( $5 \mathrm{mg} / \mathrm{kg}$ ). No changes were observed in mice treated with vehicle nanocapsules (ULNCs) when compared with mice in the LPS group.

\section{RSV-LNCs inhibit LPS-induced tissue oxidative stress}

To assess the effect of RSV-LNCs on LPS-induced oxidative stress, we evaluated the levels of MDA and SOD enzyme activity that appeared elevated following provocation (Figure 7A and B, respectively), with both changes clearly prevented by nanostructured RSV but not by free $\mathrm{RSV}(5 \mathrm{mg} / \mathrm{kg})$.

\section{Molecular mechanisms underlying RSV anti-inflammatory effects}

The ability of RSV to modulate several inflammatory molecular pathways is extensively described in the literature. ${ }^{46}$ Western blot analyses of the Akt and ERK pathways showed an increase in the phosphorylated form of both proteins after challenge with LPS (Figure 8A and B, respectively). Notably, only pretreatment with RSV-LNCs and not pretreatment with free RSV (5 mg/kg) inhibited both LPS-induced Akt and ERK phosphorylation. Density measurements are shown as the ratio of phosphorylated protein to total protein for Akt and ERK (Figure 8C and D, respectively).

\section{Discussion}

ARDS is a complex inflammatory airway disease characterized by disruption of the alveolar/endothelial barrier associated with massive pulmonary infiltration of neutrophils., ${ }^{4,9}$ Using a murine model of ALI triggered by LPS, we 


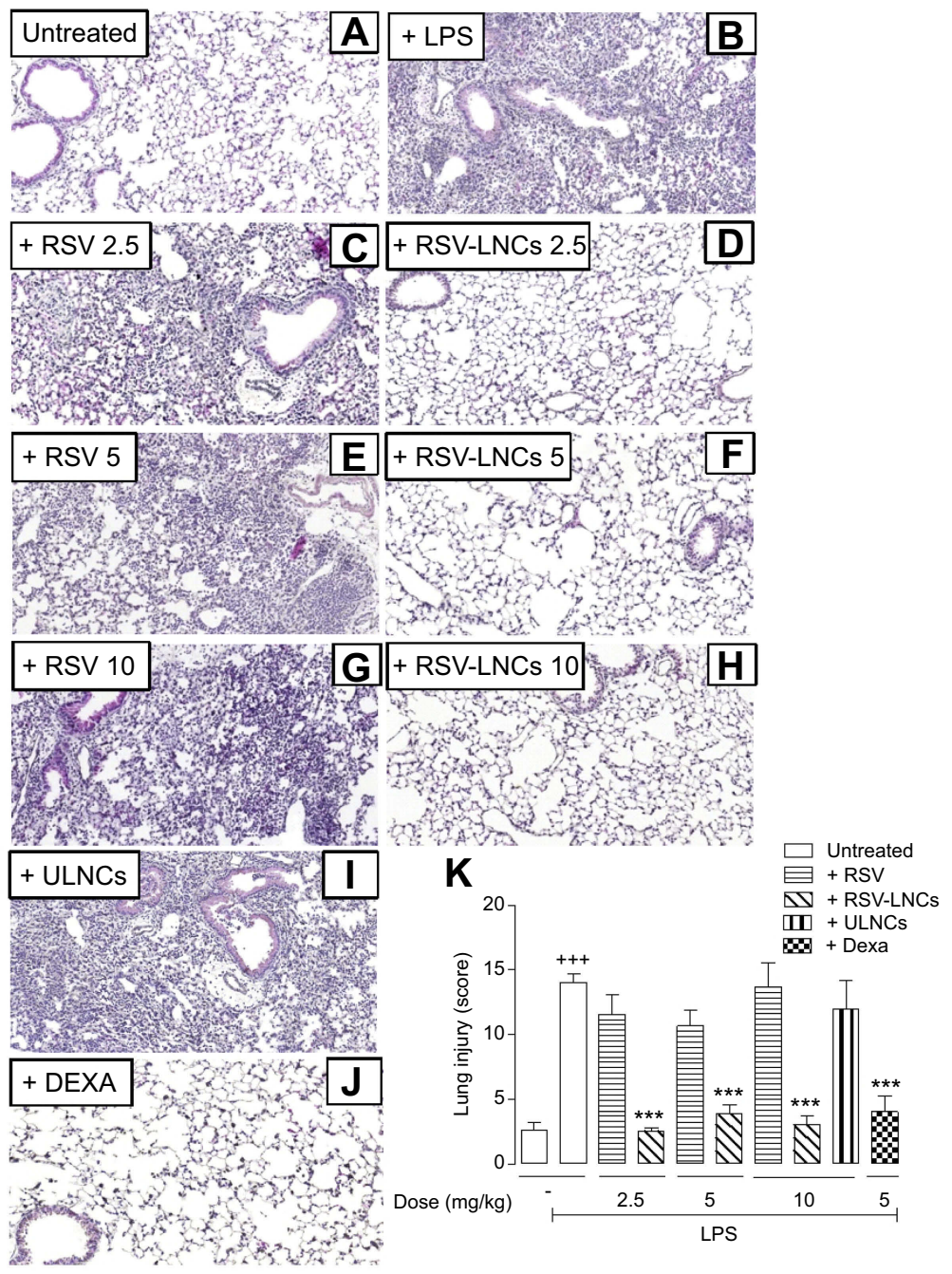

Figure 4 Effect of treatment with RSV or RSV-LNCs on lung pathological changes. A/J mice were orally pretreated with RSV, RSV-LNCs (2.5-10 mg/kg),ULNCs or Dexa $(5 \mathrm{mg} / \mathrm{kg}) 4 \mathrm{~h}$ before challenge with LPS. Analyses were performed $24 \mathrm{~h}$ after LPS stimulation. (A-J) Representative images of LPS-induced pathological changes and (K) analysis of lung damage by semiquantitative score system.

Notes: Data are expressed as the mean \pm SEM $(n=5-7) .{ }^{+++} P<0.001$ compared with the saline group and $* * * P<0.001$ compared to the LPS group. Abbreviations: RSV, resveratrol; RSV-LNCs, resveratrol-loaded lipid-core nanocapsules; Dexa, dexamethasone; LPS, lipopolysaccharide.

demonstrated in this study that the oral administration of nanoencapsulated RSV (RSV-LNCs) inhibited important features of ARDS, including neutrophil infiltration into the alveoli, release of pro-inflammatory cytokines, tissue damage and oxidative stress, by inhibiting ERK/PI3K/Akt intracellular pathways. Since free RSV was clearly less effective than the nanostructured substance, these findings suggest that nanostructuration in biodegradable oil-core polymers might be a means to improve the potency and efficacy of RSV treatment in ARDS.

The growing interest in the biological activity of RSV has resulted in a number of in vitro and animal studies that demonstrate the numerous beneficial properties of this plant-derived molecule in many diseases. Nevertheless, the putative clinical application of RSV has limitations regarding its bioavailability, which has been associated with its poor water solubility and stability as well as strong hepatic metabolism. ${ }^{47,48}$ We then tested the effectiveness of using polymeric oil-core nanocapsules to deliver RSV in the context of LPS-induced ALI. Nanocapsules used for drug delivery hold biomedical interest mainly because they provide protection against enzyme degradation and acid hydrolysis in the stomach, in addition to other advantages such as controlled release, drug targeting capacity, low toxicity, high efficacy and allowance for stable aqueous dispersion of poorly soluble molecular agents. ${ }^{49,50}$ The use of nanocarriers has already been approved for clinical use in the US and Europe, especially for cancer 

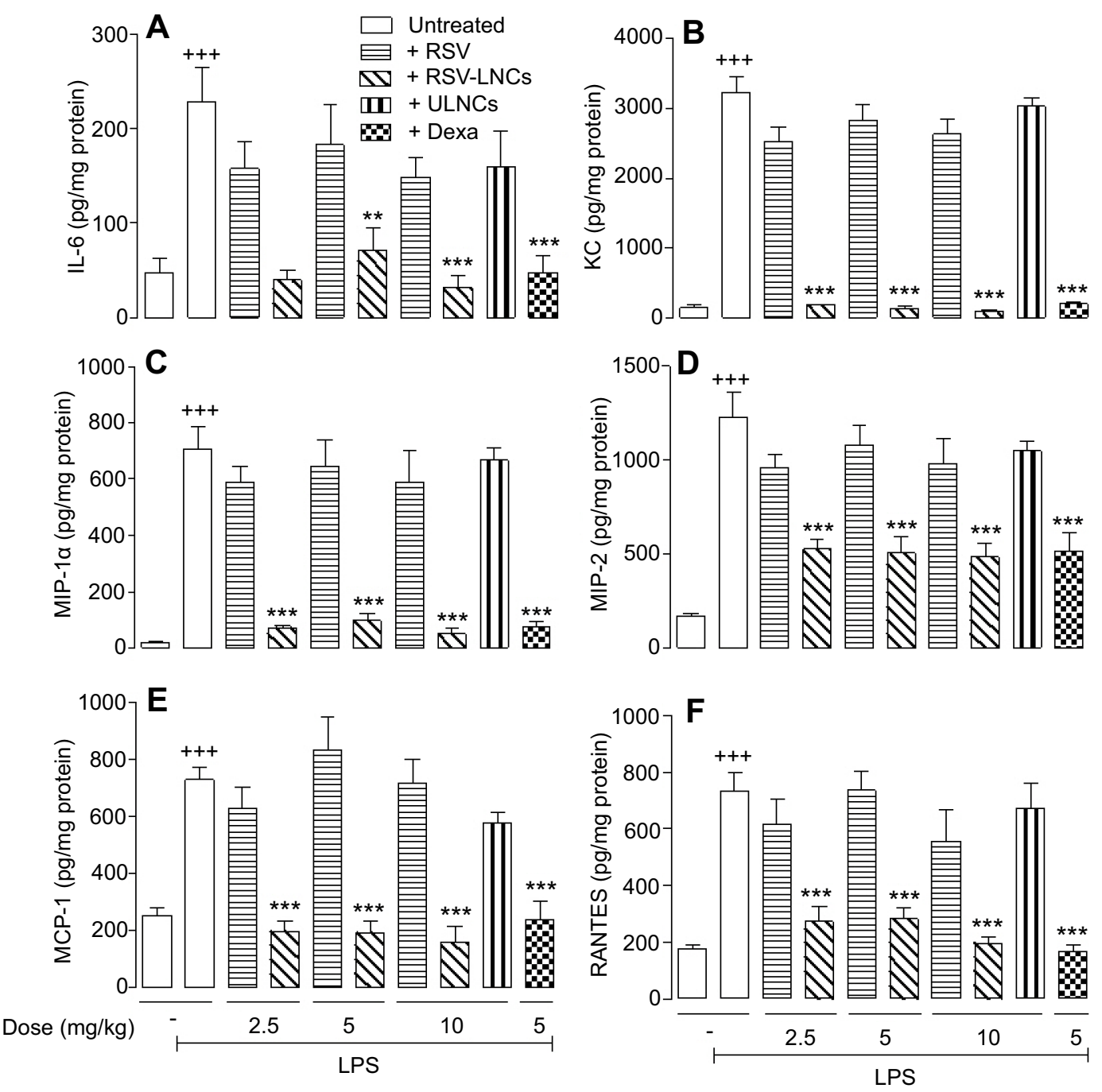

Figure 5 Effect of treatment with RSV or RSV-LNCs on lung tissue production of IL-6 (A), KC (B), MIP-I $\alpha$ (C), MIP-2 (D), MCP-I (E) and RANTES (F). A/J mice orally pretreated with RSV, RSV-LNCs $(2.5-10 \mathrm{mg} / \mathrm{kg})$, ULNCs or Dexa $(5 \mathrm{mg} / \mathrm{kg}) 4 \mathrm{~h}$ before challenge with LPS. Analyses were performed $24 \mathrm{~h}$ after LPS stimulation. Notes: Data are expressed as the mean \pm SEM $(n=5-7) .{ }^{+++} P<0.001$ compared with the saline group; $* * P<0.01$ and $* * * P<0.001$ compared to the LPS group. Abbreviations: RSV, resveratrol; RSV-LNCs, resveratrol-loaded lipid-core nanocapsules; Dexa, dexamethasone; LPS, lipopolysaccharide.

therapy. $^{51,52}$ To define the best temporal scheme of treatment required for the RSV-LNCs anti-inflammatory effect, mice were treated at different time points prior to LPS instillation. Our results indicated that treatments carried out from $4 \mathrm{~h}$ to $12 \mathrm{~h}$ before provocation abolished LPSinduced leukocyte accumulation in the BAL fluid, whereas the effectiveness was no more than $35 \%$ when the treatment was done $1 \mathrm{~h}$ before LPS challenge. These findings indicated that the nanostructured RSV is indeed much more effective than the free RSV in preventing lung leukocyte recruitment caused by LPS in this model. It does not mean that free RSV is not active per se against ALI. In fact, prior investigation has demonstrated that RSV indeed has a partially protective effect against LPS-induced
ALI, ${ }^{53}$ but this requires a much higher dose $(45 \mathrm{mg} / \mathrm{kg}$, every day for 3 days before LPS challenge) and exhibits lower efficacy than the nanostructured RSV. These findings then led us to establish the appropriate therapeutic window concerning the effectiveness of our RSV nanoformulation, ie, a time period of at least $4 \mathrm{~h}$ is required for the active principle to promote the protective effect in the lung. Since RSV-LNCs treatment was no longer effective when given $24 \mathrm{~h}$ before LPS challenge, the possibility does exist that RSV may have been released and metabolized within $24 \mathrm{~h}$ and thus is not able to reach the lung tissue at a sufficient concentration to prevent the LPSinduced inflammatory response. Actually, it is wellestablished that drug release from nanocapsules is driven 


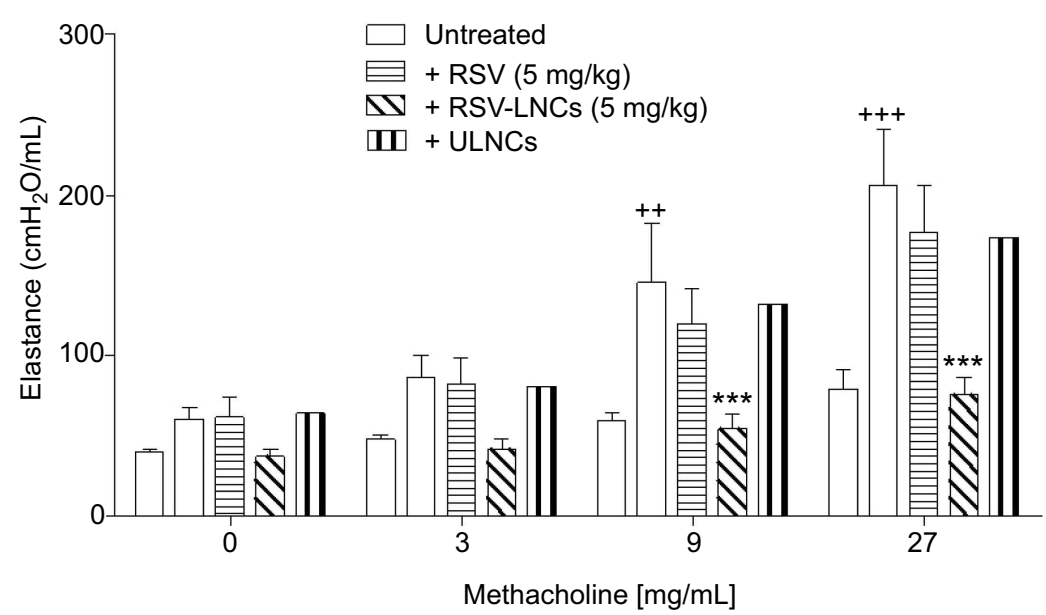

Figure 6 Effect of treatment with RSV or RSV-LNCs on airway hyperresponsiveness. A/J mice orally pretreated with RSV, RSV-LNCs (5 mg/kg) or ULNCs $4 \mathrm{~h}$ before challenge with LPS. Analyses were performed $24 \mathrm{~h}$ after LPS stimulation.

Notes: Data are expressed as the mean \pm SEM $(n=5-7) .{ }^{++} P<0.01$ and ${ }^{+++} P<0.001$ compared with the saline group and $* * * P<0.001$ compared to the LPS group. Abbreviations: RSV, resveratrol; RSV-LNCs, resveratrol-loaded lipid-core nanocapsules; LPS, lipopolysaccharide.

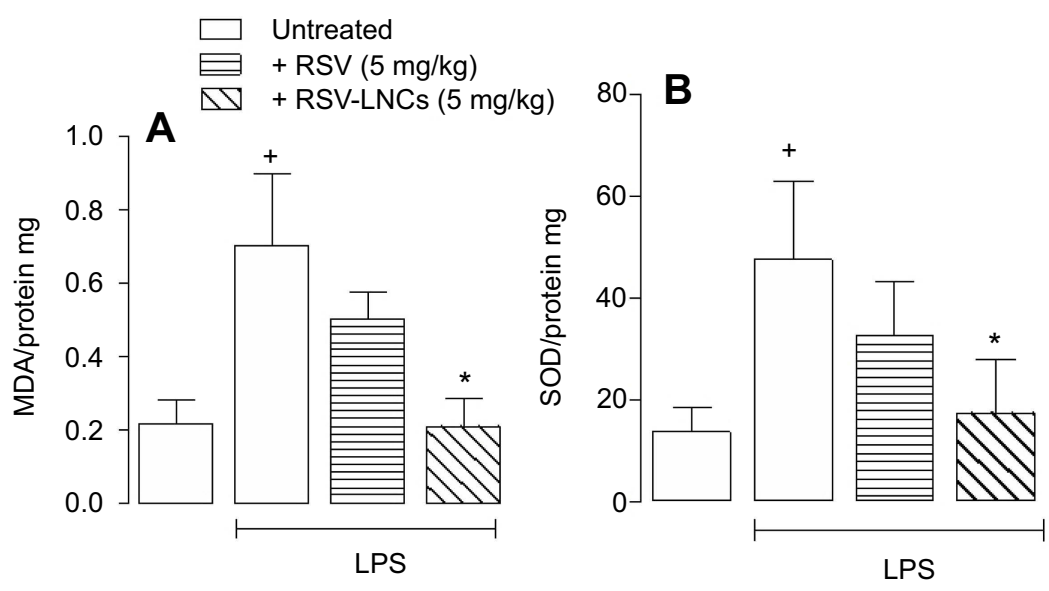

Figure 7 Effect of treatment with RSV or RSV-LNCs on lung MDA levels (A) and SOD activity (B). A/J mice orally pretreated with RSV or RSV-LNCs (5 mg/kg) $4 \mathrm{~h}$ before challenge with LPS. Analyses were performed $24 \mathrm{~h}$ after LPS stimulation.

Notes: Data are expressed as the mean \pm SEM $(n=5-7) .{ }^{+} P<0.05$ compared with the saline group and $* P<0.05$ compared to the LPS group.

Abbreviations: RSV, resveratrol; RSV-LNCs, resveratrol-loaded lipid-core nanocapsules; MDA, malondialdehyde; SOD, superoxide dismutase; LPS, lipopolysaccharide.

by several factors that lead to polymer biodegradation and consequently drug diffusion out of the matrix, which can occur in a few hours or over days. ${ }^{54-56}$

Neutrophil infiltration into the lungs in response to activated alveolar macrophages is observed in numerous experimental models and ARDS patients and is associated with disease severity. ${ }^{57,58}$ Once activated, these cells release cytotoxic molecules, including granular enzymes such as MPO, reactive oxygen species (ROS), lipid mediators and cytokines. ${ }^{57,59}$ The resulting endothelial dysfunction and rupture are responsible for the major clinical manifestations of the syndrome. ${ }^{60}$ We found that a single pretreatment with RSV-LNCs $4 \mathrm{~h}$ before LPS challenge was able to abolish LPS-induced neutrophil migration into the lungs and histological changes under conditions where empty nanocapsules or free RSV were inactive. A significant but not complete block of LPSinduced neutrophil infiltration has been reported following oral RSV ( $45 \mathrm{mg} / \mathrm{kg}$ every day for 3 days before LPS challenge). ${ }^{53}$

The presence of pro-inflammatory cytokines is closely associated with the presence of leukocytes, mainly neutrophils, at the inflamed site, and plays an important role during ARDS pathology. ${ }^{61}$ Increased levels of IL-6 are 

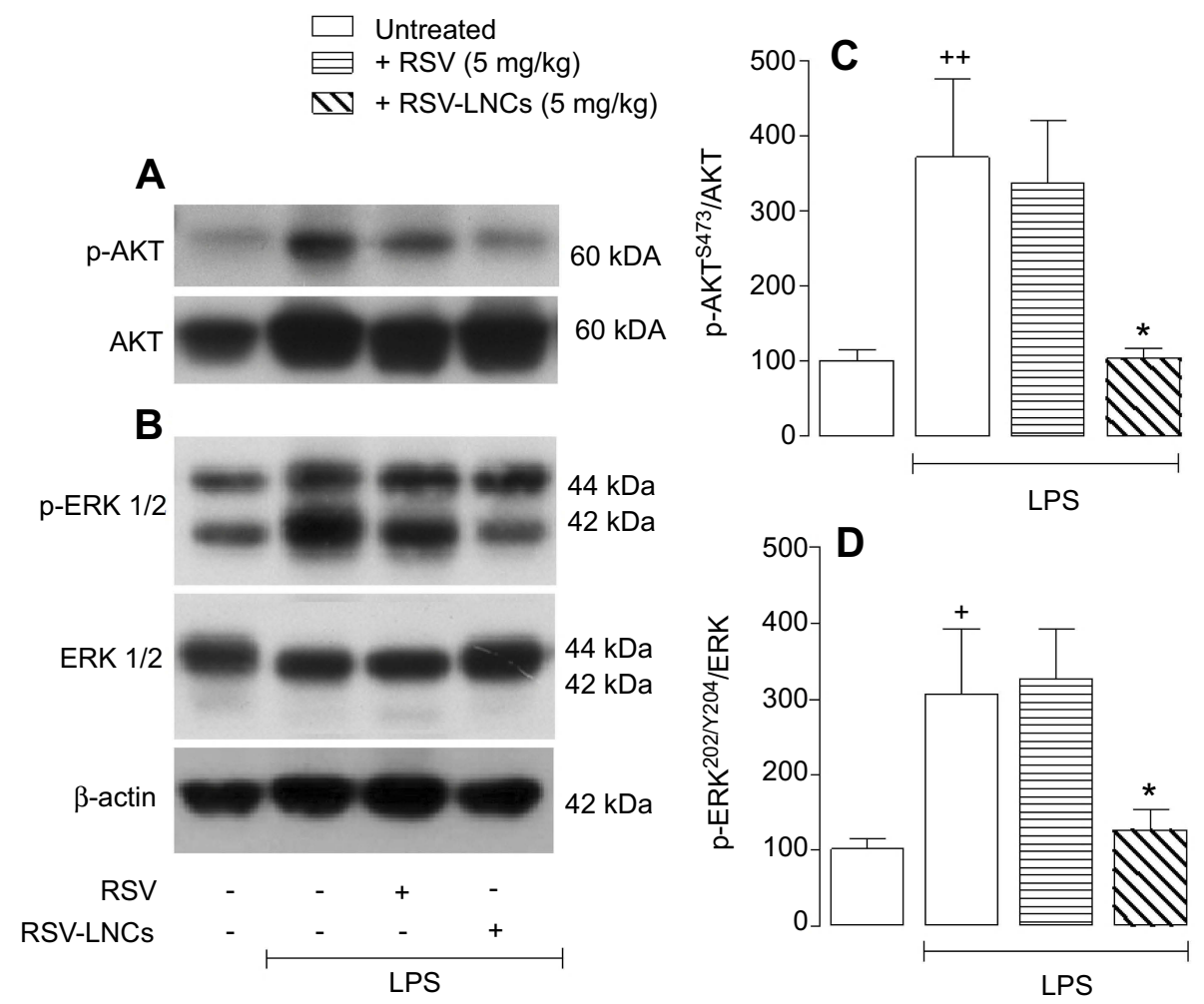

Figure 8 Western blot analysis of AKT (A) and ERK (B) phosphorylation in A/l mice orally pretreated with RSV or RSV-LNCs (5 mg/kg) $4 \mathrm{~h}$ before challenge with LPS. (C) and (D) demonstrate the densitometric values obtained for the phosphorylated and total protein of AKT and ERK, respectively. Treatments were normalized to their respective controls that were not exposed to LPS (control bar; 100\%). Analyses were performed $24 \mathrm{~h}$ after LPS stimulation. Data are expressed as a ratio of the normalized percentages of phosphorylated and total protein.

Notes: Bars represent the mean \pm SEM $(n=5-7) .{ }^{+} P<0.05$ and ${ }^{++} P<0.01$ compared with the saline group, ${ }^{*} P<0.05$ compared to the LPS group.

Abbreviations: RSV, resveratrol; RSV-LNCs, resveratrol-loaded lipid-core nanocapsules; LPS, lipopolysaccharide.

associated with worsening ARDS clinical condition, and high levels of MIP- $1 \alpha$ are found in ARDS patients' BALF. $^{61,62}$ Levels of neutrophil chemokines such as MIP-2, KC, RANTES and MCP-1 ${ }^{63-66}$ are also elevated in both patients with ARDS and experimental models of ARDS. ${ }^{64,67-69}$ We found that pretreatment with RSVLNCs inhibited LPS-induced proinflammatory cytokines, corroborating the data indicating reduced leukocyte accumulation. The inhibition of these mediators plays an important role in resolving the acute lung inflammatory response.

Pulmonary physiological changes manifest directly in alterations to respiratory mechanics. Enhanced pulmonary elastance and AHR are important clinical features of ARDS and contribute to the pulmonary complications of this syndrome. ${ }^{70,71}$ Increased AHR to nonspecific bronchoconstrictor agents can be trigged by LPS via TLR4 activation in animal models and is thought to contribute to AHR in lung diseases such as asthma and ARDS. ${ }^{67}$ We showed here increased pulmonary hyperreactivity in the elastance parameter $24 \mathrm{~h}$ after LPS instillation, which was prevented by
RSV-LNCs treatment. Together, our data prove that RSV nanoencapsulation is capable of inhibiting both the inflammatory process and changes in lung mechanics induced by LPS.

Both experimental and clinical evidence demonstrate the role of oxidants in the pathogenesis of ARDS. ${ }^{68,69}$ The oxidative imbalance induces the production of ROS, which in turn leads to uncontrolled lipid peroxidation, generating aldehyde products such as MDA. ${ }^{72}$ In response, cells express endogenous antioxidants (SOD, catalase and glutathione peroxidase) to neutralize free radicals and their effects. ${ }^{68,73}$ In addition to its anti-inflammatory activity, RSV has a well-described antioxidant effect. ${ }^{26}$ Previous data show that $30 \mathrm{mg} / \mathrm{kg}$ of RSV inhibited MDA levels and increased SOD activity when given $1 \mathrm{~h}$ after sepsis-induced lung injury. ${ }^{74}$ We demonstrated that endotoxemic lungs pretreated with RSV-LNCs exhibited low levels of MDA and reduced SOD activity. Although RSV is known as to induce SOD enzyme, ${ }^{75}$ such inhibition here may be a consequence of an improvement in inflammation and oxidative conditions, reducing the need for antioxidant defense system activation. This phenomenon has been seen previously. ${ }^{76}$ 
The biological benefit of RSV seems to be strongly related to its capacity to simultaneously modulate multiple molecular targets. ${ }^{46} \mathrm{RSV}$ effects have been related to the $\mathrm{PI} 3 \mathrm{~K} / \mathrm{Akt}$ and mitogen-activated protein kinase (MAPK) pathways, among others, including the extracellular signal regulated kinases 1 and 2 (ERK1/2) ${ }^{77}$ Both the PI3K/Akt and MAPK intracellular cascades can be initiated by LPSTRL4 receptor activation, ${ }^{78}$ leading to gene transcription and proinflammatory cytokine production. ${ }^{79}$ Considering the anti-inflammatory effect of RSV-LNCs on the modulation of pulmonary inflammation, we sought to confirm the RSV-associated molecular mechanisms by Western blot analysis. We detected a significant reduction in the phosphorylated forms of both ERK1/2 and Akt (Ser473) proinflammatory proteins in lung samples of RSV-LNCs-treated mice. Such inhibition may be the mechanism that led to the reduction of inflammatory cytokines observed in lung tissue after treatment with RSV-LNCs. Since it is recognized that phosphorylation of Akt at Ser473 promotes PI3K/Akt pathway activation, ${ }^{78}$ we propose that the antiinflammatory effect observed in pretreatment with RSVLNCs is related to negative regulation of the PI3K/Akt and ERK1/2 pathways. These findings were similar to those of previous studies that demonstrated RSV inhibition of phosphorylated protein ERK1/2 in LPS-induced lung injury ${ }^{80}$ and inhibition of Akt signaling in cancer cells exhibiting hyperactivated PI3K/Akt signaling. ${ }^{81}$

The pharmacological effects of RSV are unquestionable due to the robust scientific data that prove its therapeutic action. The promising effect of this molecule is its ability to interact with a wide range of molecular targets, which can be attributed to its relatively simple chemical structure and high permeability that facilitate its passage through biological membranes. ${ }^{21}$ However, it is important to note that, compared to the RSV doses used in this study, RSV is often administered in larger doses by a less metabolic route, ${ }^{82,83}$ and long therapeutic regimens are used when RSV is administered orally; ${ }^{53}$ in these regimes, RSV does not exhibit complete improvement of the inflammatory parameters. Here, we showed a significant improvement of the RSV anti-inflammatory effect when delivered orally in nanocapsules, with reduced or nonexistent effects seen when RSV is delivered in its free form. Therefore, we confirm that nanostructuration increases the bioavailability of RSV due to the unique benefits of nanotechnology for drug delivery, such as protection, sustained release and vectorization.

\section{Conclusion}

Taken together, our findings provide evidence that delivering RSV by polymeric nanocapsules optimizes its antiinflammatory effect to prevent ALI by inhibiting the ERK and PI3K/Akt pathways. This nanostructuration strategy proved to be crucial for improving the effect of RSV administered orally at low doses. Therefore, we propose RSV nanoformulation as a potential therapy for ARDS. Further evaluation should be performed to better understand the RSV release mechanisms from nanocapsules and the detailed molecular mechanisms of its antiALI effect.

\section{Acknowledgments}

This study was supported by the Brazilian Foundation Conselho Nacional de Desenvolvimento Científico e Tecnológico (CNPq-401859/2015-0) and Carlos Chagas Filho Foundation for Research Support of the State of Rio de Janeiro (FAPERJ/JCNE-E-26/203.195/2016).

\section{Disclosure}

MTP de Oliveira and DS Coutinho were fellows from CAPES. ET de Souza was the recipient of a FAPERJ postdoctoral fellowship. The authors report no other conflicts of interest related to this work.

\section{References}

1. Okin D, Medzhitov R. Evolution of inflammatory diseases. Curr Biol. 2012;22(17):R733-R740. doi:10.1016/j.cub.2012.07.029

2. Hunter P. The inflammation theory of disease. The growing realization that chronic inflammation is crucial in many diseases opens new avenues for treatment. EMBO Rep. 2012;13(11):968-970. doi:10.1038/embor.2012.142

3. Chen H, Bai C, Wang X. The value of the lipopolysaccharide-induced acute lung injury model in respiratory medicine. Expert Rev Respir Med. 2010;4(6):773-783. doi:10.1586/ers.10.71

4. Mirzapoiazova T, Kolosova IA, Moreno L, Sammani S, Garcia JG, Verin AD. Suppression of endotoxin-induced inflammation by taxol. Eur Respir J. 2007;30(3):429-435. doi:10.1183/09031936. 00154206

5. Morris M, Li L. Molecular mechanisms and pathological consequences of endotoxin tolerance and priming. Arch Immunol Ther Exp (Warsz). 2012;60(1):13-18. doi:10.1007/s00005-011-0155-9

6. Fard N, Saffari A, Emami G, Hofer S, Kauczor HU, Mehrabi A. Acute respiratory distress syndrome induction by pulmonary ischemia-reperfusion injury in large animal models. J Surg Res. 2014;189(2):274-284. doi:10.1016/j.jss.2014.02.034

7. Boyle AJ, McNamee JJ, McAuley DF. Biological therapies in the acute respiratory distress syndrome. Expert Opin Biol Ther. 2014;14 (7):969-981. doi:10.1517/14712598.2014.905536

8. Gattinoni L, Cressoni M, Brazzi L. Fluids in ARDS: from onset through recovery. Curr Opin Crit Care. 2014;20(4):373-377. doi:10.1097/MCC.0000000000000105 
9. Fanelli V, Vlachou A, Ghannadian S, Simonetti U, Slutsky AS, Zhang H. Acute respiratory distress syndrome: new definition, current and future therapeutic options. J Thorac Dis. 2013;5(3):326-334. doi:10.3978/j.issn.2072-1439.2013.04.05

10. Takaoka M. Resveratrol, a new phenolic compound, from veratrum grandiflorum. J. Chem. Soc. Jpn.. 1939;60:1090-1100.

11. Fremont L. Biological effects of resveratrol. Life Sci. 2000;66 (8):663-673

12. Nguyen C, Savouret JF, Widerak M, Corvol MT, Rannou F. Resveratrol, potential therapeutic interest in joint disorders: a critical narrative review. Nutrients. 2017;9(1). doi:10.3390/nu9010045

13. Catalgol B, Batirel S, Taga Y, Ozer NK. Resveratrol: French paradox revisited. Front Pharmacol. 2012;3:141. doi:10.3389/ fphar.2012.00141

14. Kursvietiene L, Staneviciene I, Mongirdiene A, Bernatoniene J. Multiplicity of effects and health benefits of resveratrol. Medicina (Kaunas). 2016;52(3):148-155. doi:10.1016/j.medici.2016.03.003

15. de Sa Coutinho D, Pacheco MT, Frozza RL, Bernardi A. Antiinflammatory effects of resveratrol: mechanistic insights. Int $\mathrm{J} \mathrm{Mol}$ Sci. 2018;19(6). doi:10.3390/ijms19061812

16. Orallo F. Comparative studies of the antioxidant effects of cis- and trans-resveratrol. Curr Med Chem. 2006;13(1):87-98.

17. Augustin MA, Sanguansri L, Lockett T. Nano- and micro-encapsulated systems for enhancing the delivery of resveratrol. Ann N Y Acad Sci. 2013;1290:107-112. doi:10.1111/nyas.12130

18. Trela BC, Waterhouse AL. Resveratrol: isomeric molar absorptivities and stability. J Agric Food Chem. 1996;44(5):1253-1257. doi:10.1021/jf9504576

19. Delmas D, Aires V, Limagne E, et al. Transport, stability, and biological activity of resveratrol. Ann N Y Acad Sci. 2011;1215:48-59. doi:10.1111/j.1749-6632.2010.05871.x

20. Pujara N, Jambhrunkar S, Wong KY, McGuckin M, Popat A. Enhanced colloidal stability, solubility and rapid dissolution of resveratrol by nanocomplexation with soy protein isolate. $J$ Colloid Interface Sci. 2017;488:303-308. doi:10.1016/j.jcis.2016.11.015

21. Brittes J, Lucio M, Nunes C, Lima JL, Reis S. Effects of resveratrol on membrane biophysical properties: relevance for its pharmacological effects. Chem Phys Lipids. 2010;163(8):747-754. doi:10.1016/j. chemphyslip.2010.07.004

22. Pentek T, Newenhouse E, O'Brien B, Chauhan SA. Development of a topical resveratrol formulation for commercial applications using dendrimer nanotechnology. Molecules. 2017;22:1. doi:10.3390/ molecules22010137

23. Kundu JK, Chun KS, Kim SO, Surh YJ. Resveratrol inhibits phorbol ester-induced cyclooxygenase-2 expression in mouse skin: mAPKs and AP-1 as potential molecular targets. Biofactors. 2004;21 (1-4):33-39.

24. Holmes-McNary M, Baldwin AS Jr. Chemopreventive properties of trans-resveratrol are associated with inhibition of activation of the IkappaB kinase. Cancer Res. 2000;60(13):3477-3483.

25. Tung BT, Rodríguez-Bies E, Ballesteros-Simarro M, Motilva V, Navas P, López-Lluch G. Modulation of endogenous antioxidant activity by resveratrol and exercise in mouse liver is age dependent. $J$ Gerontol. 2014;69(4):398-409. doi:10.1093/gerona/glt102

26. de la Lastra CA, Villegas I. Resveratrol as an antioxidant and pro-oxidant agent: mechanisms and clinical implications. Biochem Soc Trans. 2007;35(5):1156-1160. doi:10.1042/BST0351156

27. Baxter RA. Anti-aging properties of resveratrol: review and report of a potent new antioxidant skin care formulation. J Cosmet Dermatol. 2008;7(1):2-7. doi:10.1111/j.1473-2165.2008.00354.x

28. Rauf A, Imran M, Butt MS, Nadeem M, Peters DG, Mubarak MS. Resveratrol as an anticancer agent: a review. Crit Rev Food Sci Nutr. 2018.58:1428-1447.

29. Das S, Das DK. Anti-inflammatory responses of resveratrol. Inflamm Allergy Drug Targets. 2007;6(3):168-173.
30. Hung LM, Chen JK, Huang SS, Lee RS, Su MJ. Cardioprotective effect of resveratrol, a natural antioxidant derived from grapes. Cardiovasc Res. 2000;47(3):549-555. doi:10.1016/s0008-6363(00) 00102-4

31. Planas JM, Alfaras I, Colom H, Juan ME. The bioavailability and distribution of trans-resveratrol are constrained by ABC transporters. Arch Biochem Biophys. 2012;527(2):67-73. doi:10.1016/j.abb.2012.06.004

32. Vargas JE, Souto AA, Pitrez PM, Stein RT, Porto BN. Modulatory potential of resveratrol during lung inflammatory disease. Med Hypotheses. 2016;96:61-65. doi:10.1016/j.mehy.2016.09.023

33. Karthikeyan S, Rajendra Prasad N, Ganamani A, Balamurugan E. Anticancer activity of resveratrol-loaded gelatin nanoparticles on NCI-H460 non-small cell lung cancer cells. Biomed Preventive Med. 2013;3(1):64-73. doi:10.1016/j.bionut.2012.10.009

34. Coimbra M, Isacchi B, van Bloois L, et al. Improving solubility and chemical stability of natural compounds for medicinal use by incorporation into liposomes. Int $J$ Pharm. 2011;416(2):433-442. doi:10.1016/j.ijpharm.2011.01.056

35. Teskac K, Kristl J. The evidence for solid lipid nanoparticles mediated cell uptake of resveratrol. Int J Pharm. 2010;390 (1):61-69. doi:10.1016/j.ijpharm.2009.10.011

36. Lu X, Ji C, Xu H, et al. Resveratrol-loaded polymeric micelles protect cells from Abeta-induced oxidative stress. Int J Pharm. 2009;375(1-2):89-96. doi:10.1016/j.ijpharm.2009.03.021

37. Frozza RL, Salbego C, Bernardi A, et al. Incorporation of resveratrol into lipid-core nanocapsules improves its cerebral bioavailability and reduces the A $\beta$-induced toxicity. Alzheimers Dement. 2011;7(4): S114. doi:10.1016/j.jalz.2011.05.286

38. Cao Q, Jing C, Tang X, Yin Y, Han X, Wu W. Protective effect of resveratrol on acute lung injury induced by lipopolysaccharide in mice. Anat Rec (Hoboken). 2011;294(3):527-532. doi:10.1002/ar.21331

39. Szarka RJ, Wang N, Gordon L, Nation PN, Smith RH. A murine model of pulmonary damage induced by lipopolysaccharide via intranasal instillation. J Immunol Methods. 1997;202(1):49-57.

40. Apl D, Pacheco de Oliveira MT, de Souza ET, et al. Alpha-bisabololloaded lipid-core nanocapsules reduce lipopolysaccharide-induced pulmonary inflammation in mice. Int $J$ Nanomedicine. 2017;12:4479-4491. doi:10.2147/IJN.S130798

41. Ferreira TP, de Arantes AC, Do Nascimento CV, et al. IL-13 immunotoxin accelerates resolution of lung pathological changes triggered by silica particles in mice. J Immunol. 2013;191(10):5220-5229. doi:10.4049/jimmunol.1203551

42. Kummerle AE, Schmitt M, Cardozo SV, et al. Design, synthesis, and pharmacological evaluation of $\mathrm{N}$-acylhydrazones and novel conformationally constrained compounds as selective and potent orally active phosphodiesterase-4 inhibitors. J Med Chem. 2012;55 (17):7525-7545. doi:10.1021/jm300514y

43. Zhu T, Wang DX, Zhang W, et al. Andrographolide protects against LPS-induced acute lung injury by inactivation of NF-kappaB. PLoS One. 2013;8(2):e56407. doi:10.1371/journal.pone.0056407

44. Draper HH, Hadley M. [43] Malondialdehyde determination as index of lipid Peroxidation. Methods Enzymol. 1990;186:421-431. Academic Press.

45. Bannister JV, Calabrese L. Assays for superoxide dismutase. Methods Biochem Anal. 1987;32:279-312.

46. Britton RG, Kovoor C, Brown K. Direct molecular targets of resveratrol: identifying key interactions to unlock complex mechanisms. Ann N Y Acad Sci. 2015;1348(1):124-133. doi:10.1111/nyas.12796

47. Chedea VS, Vicas SI, Sticozzi C, et al. Resveratrol: from diet to topical usage. Food Funct. 2017;8(11):3879-3892. doi:10.1039/c7fo01086a

48. Pirola L, Frojdo S. Resveratrol: one molecule, many targets. IUBMB Life. 2008;60(5):323-332. doi:10.1002/iub.47

49. Chen G, Roy I, Yang C, Prasad PN. Nanochemistry and nanomedicine for nanoparticle-based diagnostics and therapy. Chem Rev. 2016;116(5):2826-2885. doi:10.1021/acs.chemrev.5b00148 
50. Poletto F, Beck R, Guterres S, Pohlmann A. Polymeric nanocapsules: concepts and applications. In: Beck RCR, Guterres SS, Pohlmann, AR, editors. Nanocosmetics and Nanomedicines: New approaches for skin care. Heidelberg: Springer Verlag; 2011:49-68.

51. Kothamasu P, Kanumur H, Ravur N, Maddu C, Parasuramrajam R, Thangavel S. Nanocapsules: the weapons for novel drug delivery systems. Bioimpacts. 2012;2(2):71-81. doi:10.5681/bi.2012.011

52. Diaspro A, Krol S, Cavalleri O, Silvano D, Gliozzi A. Microscopical characterization of nanocapsules templated on ionic crystals and biological cells toward biomedical applications. IEEE Trans Nanobioscience. 2002;1(3):110-115.

53. Zhang Z, Chen N, Liu JB, et al. Protective effect of resveratrol against acute lung injury induced by lipopolysaccharide via inhibiting the myd88-dependent Toll-like receptor 4 signaling pathway. Mol Med Rep. 2014;10(1):101-106. doi:10.3892/mmr.2014.2226

54. Kamaly N, Yameen B, Wu J, Farokhzad OC. Degradable controlled-release polymers and polymeric nanoparticles: mechanisms of controlling drug release. Chem Rev. 2016;116 (4):2602-2663. doi:10.1021/acs.chemrev.5b00346

55. Lee JH, Yeo Y. Controlled drug release from pharmaceutical nanocarriers. Chem Eng Sci. 2015;125:75-84. doi:10.1016/j.ces.2014.08.046

56. Lanz-Landazuri A, Portilla-Arias J, Martinez de Ilarduya A, et al. Nanoparticles of esterified polymalic acid for controlled anticancer drug release. Macromol Biosci. 2014;14(9):1325-1336. doi:10.1002/ mabi.201400124

57. Fujishima S. Pathophysiology and biomarkers of acute respiratory distress syndrome. J Intensive Care. 2014;2(1):32. doi:10.1186/20520492-2-32

58. Williams AE, Chambers RC. The mercurial nature of neutrophils: still an enigma in ARDS? Am J Physiol Lung Cell Mol Physiol. 2014;306(3):L217-230. doi:10.1152/ajplung.00311.2013

59. Uchiba M, Okajima K, Murakami K, Okabe H, Takatsuki K. Endotoxin-induced pulmonary vascular injury is mainly mediated by activated neutrophils in rats. Thromb Res. 1995;78(2):117-125.

60. Chabot F, Mitchell JA, Gutteridge JM, Evans TW. Reactive oxygen species in acute lung injury. Eur Respir J. 1998;11(3):745-757.

61. Dinarello CA. Historical Review of Cytokines. Eur J Immunol. 2007;37(Suppl 1):S34-S45. doi:10.1002/eji.200737772

62. Goodman RB, Strieter RM, Martin DP, et al. Inflammatory cytokines in patients with persistence of the acute respiratory distress syndrome. Am J Respir Crit Care Med. 1996;154(3 Pt 1):602-611. doi:10.1164/ajrccm.154.3.8810593

63. De Filippo K, Henderson RB, Laschinger M, Hogg N. Neutrophil chemokines $\mathrm{KC}$ and macrophage-inflammatory protein- 2 are newly synthesized by tissue macrophages using distinct TLR signaling pathways. J Immunol. 2008;180(6):4308-4315. doi:10.4049/jimmunol.180.6.4308

64. Pan ZZ, Parkyn L, Ray A, Ray P. Inducible lung-specific expression of RANTES: preferential recruitment of neutrophils. Am J Physiol Lung Cell Mol Physiol. 2000;279(4):L658-666. doi:10.1152/ ajplung.2000.279.4.L658

65. Tumpey TM, Fenton R, Molesworth-Kenyon S, Oakes JE, Lausch RN. Role for macrophage inflammatory protein 2 (MIP-2), MIP-1alpha, and interleukin-1alpha in the delayed-type hypersensitivity response to viral antigen. $J$ Virol. 2002;76(16):8050-8057. doi:10.1128/jvi.76.16.8050-8057.2002

66. Balamayooran G, Batra S, Balamayooran T, Cai S, Jeyaseelan S. Monocyte chemoattractant protein 1 regulates pulmonary host defense via neutrophil recruitment during Escherichia coli infection. Infect Immun. 2011;79(7):2567-2577. doi:10.1128/IAI.00067-11
67. Brass DM, Hollingsworth JW, McElvania-Tekippe E, Garantziotis S, Hossain I, Schwartz DA. CD14 is an essential mediator of LPS-induced airway disease. Am J Physiol Lung Cell Mol Physiol. 2007;293(1):L77-L83. doi:10.1152/ajplung.00282.2006

68. Chow CW, Herrera Abreu MT, Suzuki T, Downey GP. Oxidative stress and acute lung injury. Am J Respir Cell Mol Biol. 2003;29 (4):427-431. doi: $10.1165 / \mathrm{rcmb} . F 278$

69. Gertz M, Nguyen GT, Fischer F, et al. A molecular mechanism for direct sirtuin activation by resveratrol. PLoS One. 2012;7(11): e49761. doi:10.1371/journal.pone.0049761

70. Held HD, Uhlig S. Mechanisms of endotoxin-induced airway and pulmonary vascular hyperreactivity in mice. Am J Respir Crit Care Med. 2000;162(4 Pt 1):1547-1552. doi:10.1164/ajrccm.162.4.9912079

71. Gattinoni L, Chiumello D, Carlesso E, Valenza F. Bench-to-bedside review: chest wall elastance in acute lung injury/acute respiratory distress syndrome patients. Crit Care. 2004;8(5):350-355. doi:10.1186/cc2854

72. Kim EN, Lim JH, Kim MY, et al. Resveratrol, an Nrf2 activator, ameliorates aging-related progressive renal injury. Aging. 2018;10 (1):83-99. doi:10.18632/aging.101361

73. Yasui K, Kobayashi N, Yamazaki T, et al. Superoxide Dismutase (SOD) as a Potential Inhibitory Mediator of Inflammation via Neutrophil Apoptosis. Free Radic. Res. 2005;39(7):755-62.

74. Wang Y, Wang X, Zhang L, Zhang R. Alleviation of acute lung injury in rats with sepsis by resveratrol via the phosphatidylinositol 3-kinase/nuclear factor-erythroid 2 related factor 2/Heme Oxygenase-1 (PI3K/Nrf2/HO-1) pathway. Med Sci Monit. 2018;24:3604-3611. doi:10.12659/MSM.910245

75. Spanier G, Xu H, Xia N, et al. Resveratrol reduces endothelial oxidative stress by modulating the gene expression of superoxide dismutase 1 (SOD1), glutathione peroxidase 1 (GPx1) and NADPH oxidase subunit (Nox4). J Physiol Pharmacol. 2009;60(Suppl 4):111-116.

76. Sadi G, Konat D. Resveratrol regulates oxidative biomarkers and antioxidant enzymes in the brain of streptozotocin-induced diabetic rats. Pharm Biol. 2016;54(7):1156-1163. doi:10.3109/13880209.2015.1056311

77. Kulkarni SS, Canto C. The molecular targets of resveratrol. Biochim Biophys Acta. 2015;1852(6):1114-1123. doi:10.1016/j. bbadis.2014.10.005

78. Qin X, Jiang X, Wang Y, et al. Micheliolide inhibits LPS-induced inflammatory response and protects mice from LPS challenge. Sci Rep. 2016;6:23240. doi:10.1038/srep23240

79. Wang X, Quinn PJ, Yan A. Kdo2 -lipid A: structural diversity and impact on immunopharmacology. Biol Rev Camb Philos Soc. 2015;90(2):408-427. doi:10.1111/brv.12114

80. Wang $\mathrm{G}, \mathrm{Hu} \mathrm{Z}, \mathrm{Fu} \mathrm{Q}$, et al. Resveratrol mitigates lipopolysaccharide-mediated acute inflammation in rats by inhibiting the TLR4/NF-kappaBp65/MAPKs signaling cascade. Sci Rep. 2017;7:45006. doi:10.1038/srep45006

81. Berman AY, Motechin RA, Wiesenfeld MY, Holz MK. The therapeutic potential of resveratrol: a review of clinical trials. NPJ Precis Oncol. 2017;1:35.

82. Zhang HX, Duan GL, Wang CN, Zhang YQ, Zhu XY, Liu YJ. Protective effect of resveratrol against endotoxemia-induced lung injury involves the reduction of oxidative/nitrative stress. Pulm Pharmacol Ther. 2014;27 (2):150-155. doi:10.1016/j.pupt.2013.07.007

83. Jiang L, Zhang L, Kang $\mathrm{K}$, et al. Resveratrol ameliorates LPS-induced acute lung injury via NLRP3 inflammasome modulation. Biomed Pharmacother. 2016;84:130-138. doi:10.1016/ j.biopha.2016.09.020 


\section{Publish your work in this journal}

The International Journal of Nanomedicine is an international, peerreviewed journal focusing on the application of nanotechnology in diagnostics, therapeutics, and drug delivery systems throughout the biomedical field. This journal is indexed on PubMed Central, MedLine, CAS, SciSearch ${ }^{\circledR}$, Current Contents ${ }^{\mathbb{B}} /$ Clinical Medicine,

Journal Citation Reports/Science Edition, EMBase, Scopus and the Elsevier Bibliographic databases. The manuscript management system is completely online and includes a very quick and fair peer-review system, which is all easy to use. Visit http://www.dovepress.com/ testimonials.php to read real quotes from published authors. 